\title{
Diwali in the HIV Ward
}

Kalyan Banda, MBBS

Department of Internal Medicine, University of California, San Diego, San Diego, CA, USA.

She wears her festivals

on her ears, hair, arms, on

gilded gold parrot cages dangling in crisp miniature

from earlobes, on freshly plucked jasmine buds in her hair

and a thin plume of its scent that formed a trail behind her,

in a magenta skirt, blouse, shiny with a silver zari:

and in the green-glass translucent bangles that drew me

and clinked every time she gesticulated.

She wears her inheritance, like her festivals

on her ears, hair, arms, on

the scarab-like lesions above silver anklets,

on her neck a scaly black pendant,

on her reedy, hollow frame, in her blood

where tiny insects exploded off ballooned cells,

each other, multiplied, grew legs, and stomped

deep through her veins, leaving a swath of destruction.

Come again, she asks. Yes

I answer. But playing a fast reel in my mind

are questions I cannot ask;

What if,

in the morning, the rickety, metal bed with peeling

white paint, is stripped of sheets clean

- the blotched brown rubber mattress showing

at angles, and the floor below being swept?

Or worse, is occupied

by another little girl, who on her ears, hair, arms

also wears her inheritance?

Corresponding Author: Kalyan Banda, MBBS; Department of Internal Medicine, University of California, San Diego, 402, Dickinson Street, San Diego, CA 92103, USA (e-mail: kbanda@ucsd.edu).

J Gen Intern Med 29(2):419

DOI: $10.1007 / \mathrm{s} 11606-013-2609-8$

(C) Society of General Internal Medicine 2013 